\title{
Response time in the emergency services. Systematic review ${ }^{1}$
}

Eric Lucas dos Santos Cabral', Wilkson Ricardo Silva Castro', Davidson Rogério de Medeiros Florentino', Danylo de Araújo Viana', João Florêncio da Costa Junior', Ricardo Pires de Souza", Amália Cinthia Meneses Rêgo"', Irami Araújo-Filho"v , Aldo Cunha Medeirosv

'Fellow Master degree, Postgraduate Program in Production Engineering, Universidade Federal do Rio Grande do Norte (UFRN), Natal-RN, Brazil. Acquisition, interpretation and analysis of data; manuscript writing.

"Fellow Master degree, Postgraduate Program in Production Engineering, UFRN, Natal-RN, Brazil. Acquisition, interpretation and analysis of data; critical revision.

I'PhD, Health Sciences, Natal-RN, Brazil. Design of the study, interpretation and analysis of data, manuscript writing, critical revision.

IVFull Professor, Department of Surgery, UFRN and Universidade Potiguar (UnP), Natal-RN, Brazil. Design of the study, interpretation and analysis of data, manuscript writing, critical revision.

VPhD, Full Professor, Department of Surgery, UFRN, Natal-RN, Brazil. Design of the study, interpretation and analysis of data, manuscript writing, critical revision.

\section{Abstract}

The growth of the urban population raises concern about municipal public managers in the sense of providing emergency medical services (EMS) that are aligned with the needs of prehospital emergency medical care demanded by the population. The literature review aims at presenting the response time of emergency medical services in several parts of the world and discussing some factors that interfere in the result of this indicator such as GDP (Gross Domestic Product) percentage spent on health and life expectancy of countries. The study will also show that in some of the consulted articles, authors suggest to EMS recommendations for decreasing the response time using simulations, heuristics and metaheuristics. Response time is a basic indicator of emergency medical services, in such a way that researchers use the descriptive statistics to evaluate this parameter. Europe and the USA outstand in the publication of studies that present this information. Some articles use stochastic and mathematical methods to suggest models that simulate scenarios of response time reduction and suggest such proposals to the local EMS. Countries in which the response time was identified have a high index of human development and life expectancy between 74.7 and 83.7 years.

Key words: Emergency Medical Services. Ambulances. Emergency Responders. 


\section{Introduction}

Growth of the urban population raises the concern of municipal public managers in the sense of providing emergency medical care services that are aligned with the needs of prehospital emergency medical care demanded by the population. There are estimates indicating that by 2050 , urban areas should have a contingent of 6.29 billion people, equivalent to $69 \%$ of the world's total population ${ }^{1}$. With population growth in large cities, it is natural that there is a significant increase in the number of traffic accidents and other serious occurrences such as heart attack, drowning, drilling by firearm and disasters (floods, landslides, earthquakes, for example).

This increase in such occurrences is reflected in the proportional growth in costs of health systems worldwide. In 2010 prognoses show that this value reached $17.6 \%$. Among these health expenditures, 5 to $10 \%$ are with emergencies $^{2-3}$. Furthermore, the increasing number of inhabitants in an urban area will challenge the resources already in place. The traffic density in many metropolitan areas of the world causes severe car congestion ${ }^{4}$.

The World Health Organization has defined provision of basic life support to all risk situations involving people and goods as a main objective of Emergency Medical Services $(E M S)^{5}$. EMS is included in this discussion as they are responsible for the provision of acute prehospital care for patients with illnesses and injuries and have a key role to providing quality services to people, minimizing the degree of lesions and even the death toll ${ }^{6}$. The response time of EMS is a fundamental factor for prehospital care to be successful and, therefore, must be controlled in order to increase the chances of survival?.

Response time is the main indicator of this service. It is defined as the time between notification of an occurrence and the ambulance arrival at the scene. According to the WHO, an ideal response time is equivalent to less than 8 minutes $^{5}$. Regarding the definition of response time, Lawner et al. ${ }^{7}$ consider secondary outcomes, which include changes in other main ambulance time metrics such as average ambulance response interval (time from ambulance dispatch to arrival at the scene) and overall out-of-service interval (the amount of time that an ambulance is not available to respond to another incident). Vile et al. ${ }^{8}$ further stresses that response times are one of WEST's Key Performance Indicators (KPIs) since they are believed to provide a good indication of the quality and timeliness of care provided by the service.

Worldwide, this parameter is quantified because of its relevance in the evaluation of quality of service. Examples identified in cities with more than one million inhabitants in Brazil and in the world explain the average response time for urgent care: in the UK, it should be a maximum of 8 minutes in $75 \%$ of calls and 19 minutes in serious, but not urgent, calls.

In Vienna, Austria, the average response time recorded in 2015 was 15 minutes considering a $10 \%$ dispersion of this value to more or less due to the restrictions of intense traffic of vehicles and climatic conditions. In Brazil, in Belo Horizonte, the average response time in 2010 was approximately 21 minutes $^{9}$. In the city of São Paulo, in 2007, the best response time found for emergency medical services was 27 minutes $^{10}$.

Takeda et al. ${ }^{11}$ discussed in their article the US EMS Act, which sets some standards: 95\% of the emergency requests should be served within $10 \mathrm{~min}$ in urban areas and within $30 \mathrm{~min}$ in rural areas. Similar regulations are found in other parts of the world; for example, in London and Montreal, the regulation states that $95 \%$ of the requests should be served within 14 to $10 \mathrm{~min}$, and $50 \%$ and $70 \%$ of the requests should be served within 8 to $7 \mathrm{~min}$, 
respectively ${ }^{6-8}$. Throughout the time, there was a tendency of growth of the publications that addressed in its scope the time of response of EMS. Figure 1 represents the continents with a larger number of publication of the selected studies for data extraction ${ }^{12}$.

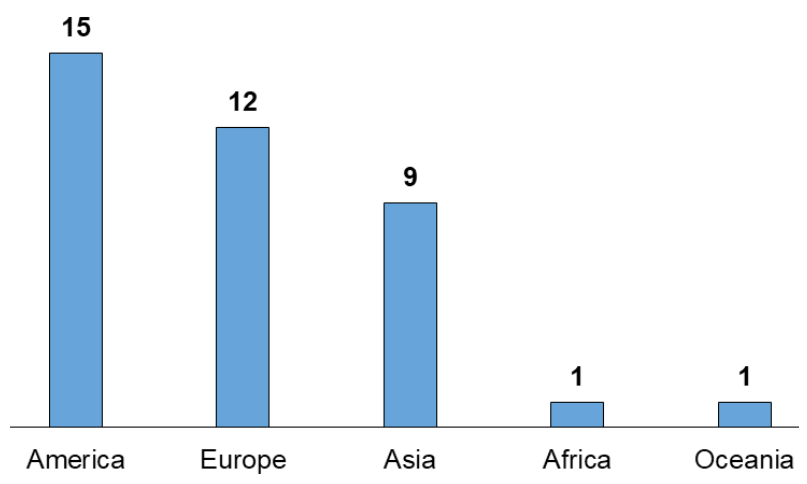

Figure 1 - Continents that outstand in the publication of response times and EMS.

It is clear that America and Europe outstand in this classification. It is necessary to point out that the figure in discussion refers to the articles that were selected by this review for presenting the information initially discussed by the authors.

The keywords identified in the articles consulted in this literature review are interrelated and allowed the meeting of technical materials that were aligned with the objective described in this review. In Figure 1 , the diameter of each node representing these words is proportional to the number of articles located regarding them. The representativeness of nodes emergency medical services, prehospital emergency care, ambulances, emergency responders, reaction time and emergency health service are significant in the contribution to studies that deepen the discussion of this review.

In order to quantify the response time of emergency medical services and, in some cases, to contribute with suggestions to reduce this indicator, the articles consulted were based on Statistical Methods and Operational Research. The objective of statistical methods is to make processes efficient as much as possible ${ }^{12}$. Statistical methods are used to understand variability. By variability, it is understood that successive observations of a system or phenomenon do not produce exactly the same result. In the search for this goal, statistic uses some tools: descriptive statistics, statistical inference, regression, correlation and multivariate analysis of the data.

Descriptive statistics, measures of central tendency; dispersion measures; measures of asymmetry and flatness; and measures of association and graphical representation of results. Also, according to, statistical inferences cover some functions of probability density that are used more frequently in statistical analysis ${ }^{13}$. The functions are Normal distribution; Distribution of the Chi-square $\left(x^{2}\right)$; Student's t-distribution; $F$ Distribution and Binomial Distribution ${ }^{12,13}$.

Regression is a valid method to understand the influence that one or more predictive variables have in relation to a regressive variable. Through it, it is possible to construct an equation that accurately predicts the future behavior that one wishes to evaluate, if parameters such as correlation coefficient between variables, F-test and $p$-value test, are satisfactory ${ }^{13}$.

Operational Research also contributes to the fact that the models developed in the articles consulted for this review reach their objectives, since one of the strategies used by EMS management to reduce response time is to use algorithms, heuristics and metaheuristics to the definition of the routes of the vehicles involved in the provision of this service ${ }^{10-12}$.

Operational Research attributed to the military services early in World War II. Due to of the war effort, there was urgent need to allocate scarce resources to the various military operations. Another characteristic 
of operations research is its broad viewpoint, encompassing Linear Programming, Dynamic Programming and Queuing Theory ${ }^{14}$.

Inserted in this context, this literature review aims to present the response time of emergency medical services (EMS) in several parts of the world and to discuss some factors that interfere in the result of this indicator such as GDP percentage spent with health as well as life expectancy of Countries. Our study will also show that in some of the articles consulted the authors suggest to the EMS recommendations to decreasing the response time using simulations, heuristics and metaheuristics.

\section{- Methods}

Scopus/Embase, NCBI (PubMed) and Science Direct were searched on 5 May 2017 for English-language papers from 2007 to 2017. The following search terms were used: "Emergency Medical Services" and "Response Time". Titles and abstracts were reviewed independently by four reviewers. The time interval considered for the evaluation of articles was from 2007 to 2017. The Lilacs database was not queried because it is indexed in SciELO, which in turn is indexed in PubMed. Google Scholar was not considered due to the preference of the review authors for the use of peer reviewed databases. It used in this research is showed in Figure 2. Disagreements between reviewers were resolved in a meeting with the rest of the research team. During the full text review, studies were excluded if they did not meet the criteria, response time availability and the referring cities. Studies were not excluded on the basis of methodological quality. The final sample size for the analysis was 205 articles, these came from 864 studies. A recent bibliometric review of scheduling routing presented relevant information regarding response time in emergency medical services with a broader number of selected articles, the mentioned review though, approached the applied methodology aiming at improving the response time. While the present study focus on the descriptive statistical analysis of the response time around the world. The reason of which the aforementioned review differs in searched articles, can be explained by the requirement of the proposition mathematical methods, demand of which is not applied in the present study.

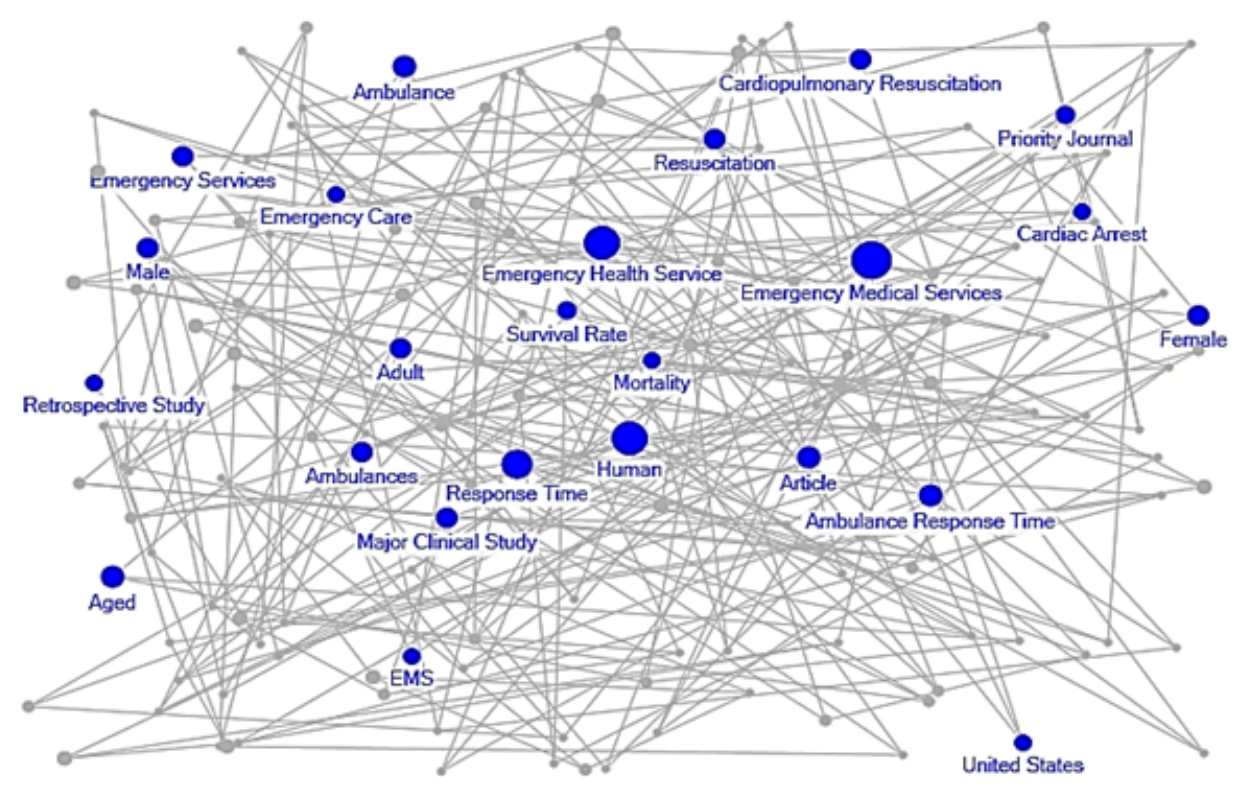

Figure 2 - Keyword found in database search. 
The research was done in the following order: the country and city where the study was carried out, the methods used to provide the reduction of the response time of the EMS, the journal that published it, year of publication of the article, country's GDP, public health expenditure percent to GDP and nationality life expectancy. Based on these data, an analysis of the elements of descriptive statistics was developed and the graphical representations of this evaluation were positioned within the scope of this study, in such a way that the conclusions expressed in it are evaluated numerically.

\section{- Results}

According to the articles listed, an international concern is observed in the measurement and optimization of response time in attending emergency occurrences that require the presence of qualified medical staff $^{15-17}$. Technical work has been found in this sense in all the habitable continents with emphasis on America and Europe. The largest portion of the articles comprise statistical analysis of the data provided by the medical emergency management agencies of the region aiming at presenting indicators of these services $^{18,19}$.

In general, local organizations that manage the emergency medical service provide the information necessary for research centers to make this assessment ${ }^{20}$. Other study will not only make basic statistical descriptions related to the EMS, but also make recommendations that will influence the performance of routine operations impacting, in particular, the service response time ${ }^{21-23}$. Figure 3 summarizes that a significant portion of the studies dealing with problems related to emergency medical services in order to contribute to decreased response time, resources, coverage and routes, for example, make use of simulation, algorithms and data analysis through descriptive statistics ${ }^{24,25}$.

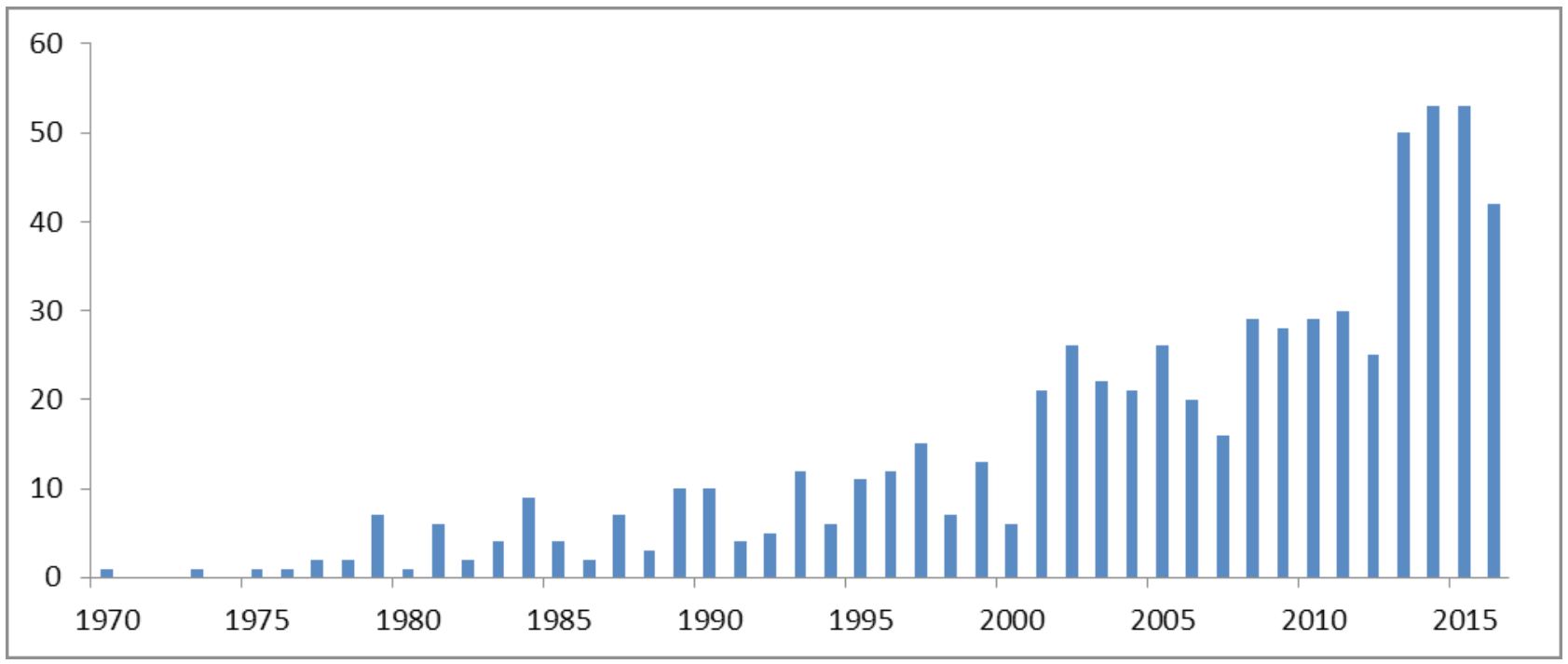

Figure 3 - Evolution of publication related to responses times and EMS. 
The use of algorithms and simulations allow scenarios to be developed and evaluated. Hence, it is possible to make changes in the characteristics of the scenarios, such as resources, variables and planning horizons, for example ${ }^{26-28}$. Non-significant methods for usability in articles related to Figure 4 (Queue Theory, for example) are more complex in the construction of scenarios and are descriptive, which makes their recurrent use unfeasible in the articles consulted ${ }^{29}$.

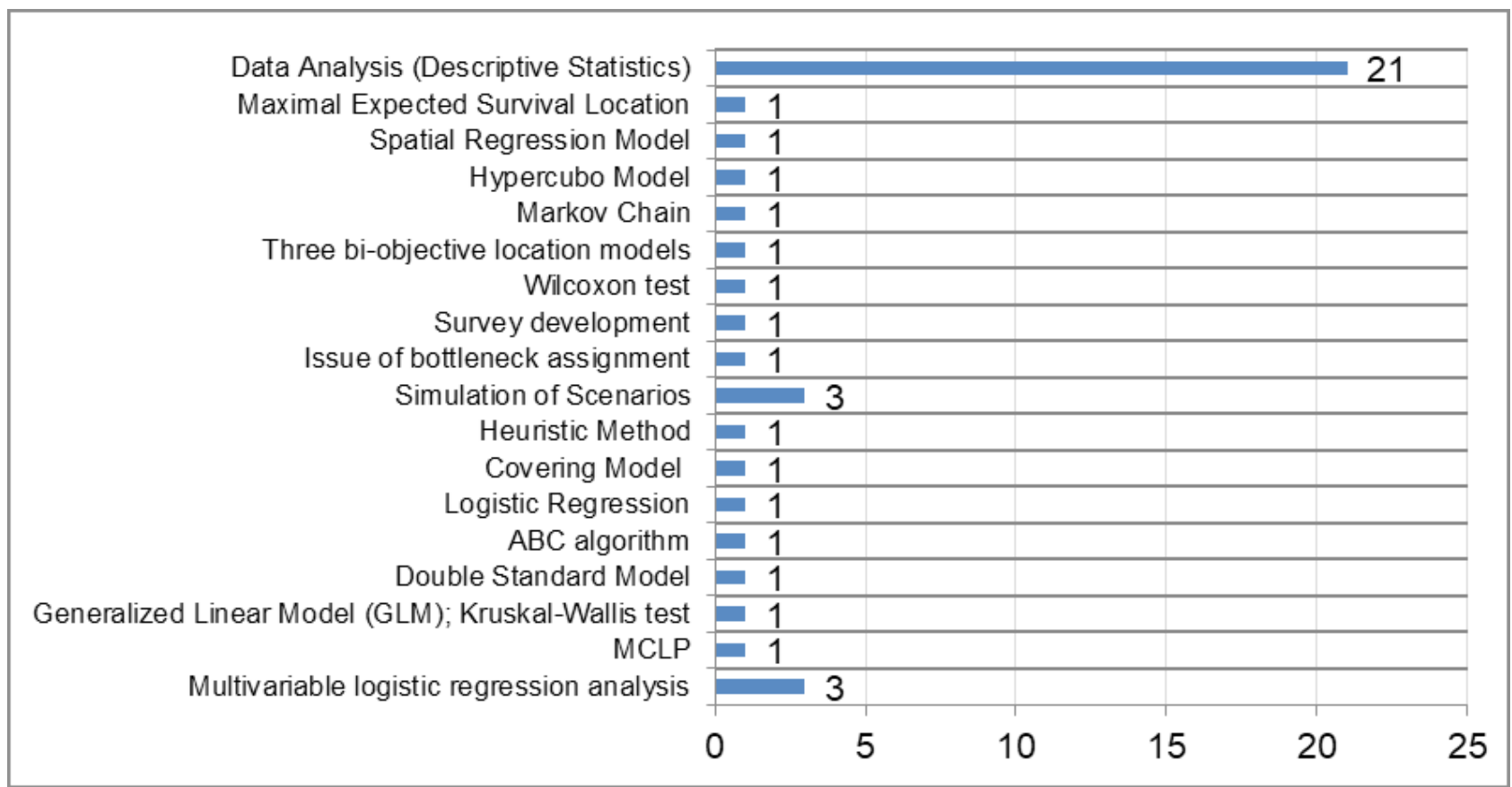

Figure 4 - Methods used in the article searched.

Data evaluation shows that the localities found, positioned mainly in Europe and North America, present a response time in accordance with what is expected for this type of service, having an estimated time of approximately 8 minutes according the $\mathrm{WHO}^{2,30-33}$.

Locations in Asia, Latin America and Africa showed response time higher than 8 minutes. Economic development and access to health influence these numbers as well as the operational conditions of the emergency medical services of those countries of the aforementioned places ${ }^{34-36}$. Table 1 shows that the localities with the shortest response time in emergency medical services were Salt Lake City (United States) and Taoyuan (Taiwan). In these cities, the use of information technology (mobile applications), significant GDP percentage spent on public health by the country and high level of schooling of the population (which could provide prehospital medical care before the arrival of ambulances), ensure that the indicator is lower than that of other countries and cities ${ }^{37}$. The locations with the longest response time were Athens and São Paulo ${ }^{10-12}$. 
Table 1 - Information listed in the articles evaluated.

\begin{tabular}{|c|c|c|c|c|c|c|}
\hline $\begin{array}{l}\text { Year of } \\
\text { publication }\end{array}$ & Countries & City. Region and State & $\begin{array}{l}\text { Response } \\
\text { Time } \\
\text { (Minutes) }\end{array}$ & HDI & $\begin{array}{c}\text { Life } \\
\text { expectancy } \\
\text { (Years) }\end{array}$ & $\begin{array}{l}\text { Public Health } \\
\text { Expenditure } \\
\text { (\% to GDP) }\end{array}$ \\
\hline 2014 & Taiwan & Taoyuan ${ }^{15}$ & 5 & 0.738 & 76.0 & 3.1 \\
\hline 2016 & United States & Salt Lake City ${ }^{16}$ & 5 & 0.920 & 79.2 & 8.3 \\
\hline 2017 & Republic of Korea & Seoul $^{17}$ & 7 & 0.901 & 82.1 & 7.4 \\
\hline 2015 & United Kingdom & $\begin{array}{l}\text { Wiltshire,Glouceste-rshire and } \\
\text { Avon in Southwest England }{ }^{18}\end{array}$ & 6 & 0.909 & 80.8 & 7.6 \\
\hline 2016 & United States & Seattle ${ }^{19}$ & 6.1 & 0.920 & 79.2 & 8.3 \\
\hline 2015 & Singapore & Singapore ${ }^{20}$ & 7.25 & 0.925 & 83.2 & 2.1 \\
\hline 2015 & Sweden & Stockholm ${ }^{21}$ & 7.8 & 0.913 & 82.3 & 10.0 \\
\hline 2012 & Australia & Melbourne ${ }^{22}$ & 8 & 0.939 & 82.5 & 6.3 \\
\hline 2016 & Netherlands & Nijmegen, Gelderland Zuid²3 & 8 & 0.924 & 81.7 & 9.5 \\
\hline 2015 & Netherlands & Amsterdam ${ }^{24}$ & 15 & 0.924 & 81.7 & 9.5 \\
\hline 2015 & Finland & Southern and Eastern Finland ${ }^{25}$ & 8 & 0.895 & 81.0 & 7.3 \\
\hline 2016 & United States & Charlotte ${ }^{26}$ & 8.59 & 0.920 & 79.2 & 8.3 \\
\hline 2011 & Portugal & Lisboa $^{27}$ & 9 & 0.843 & 81.2 & 6.2 \\
\hline 2012 & Canada & Edmonton ${ }^{28}$ & 9 & 0.920 & 82.2 & 7.4 \\
\hline 2014 & United States & Hanover ${ }^{29}$ & 9 & 0.920 & 79.2 & 8.3 \\
\hline 2016 & United States & Chicago $^{30,31}$ & 10 & 0.920 & 79.2 & 8.3 \\
\hline 2015 & Norway & Bergen $^{32}$ & 11 & 0.949 & 81.7 & 9.7 \\
\hline 2013 & Switzerland & Berna ${ }^{33}$ & 11.5 & 0.939 & 83.1 & 7.7 \\
\hline 2017 & Mexico & Tijuana ${ }^{34}$ & 14 & 0.762 & 77.0 & 3.3 \\
\hline 2013 & United States & Alabama $^{35}$ & 6.4 & 0.920 & 79.2 & 8.3 \\
\hline 2016 & Netherlands & Flevoland $^{36}$ & 15 & 0.924 & 81.7 & 9.5 \\
\hline 2014 & Spain & Galícia $^{37}$ & 15 & 0.884 & 82.8 & 6.4 \\
\hline 2014 & Iran (Islamic Republic of) & Tabriz ${ }^{38}$ & 17.87 & 0.774 & 75.6 & 2.8 \\
\hline 2016 & Ghana & Kumasi, Accra and Tamale $\mathrm{e}^{39}$ & 19.5 & 0.579 & 62.5 & 3.6 \\
\hline 2016 & Brazil & Belo Horizonte $\mathrm{e}^{5}$ & 21 & 0.754 & 74.7 & 3.8 \\
\hline 2014 & United States & Dallas $^{40}$ & 24 & 0.920 & 79.2 & 8.3 \\
\hline 2016 & United States & Baltimore $^{41}$ & 25.1 & 0.920 & 79.2 & 7.8 \\
\hline 2013 & Spain & Navarre $^{42}$ & 26 & 0.884 & 82.8 & 6.4 \\
\hline 2015 & Brazil & São Paulo ${ }^{10}$ & 27 & 0.754 & 74.7 & 3.8 \\
\hline 2007 & Brazil & Campinas $^{11}$ & 13 & 0.754 & 74.7 & 3.8 \\
\hline 2014 & Turkey & Eskisehir ${ }^{43}$ & 6.5 & 0.767 & 75.5 & 4.2 \\
\hline 2015 & Iran (Islamic Republic of) & Shiraz ${ }^{4}$ & 8.83 & 0.774 & 75.6 & 2.8 \\
\hline 2016 & Japan & All of Japan ${ }^{44,45}$ & 7.5 & 0.903 & 83.7 & 10.2 \\
\hline 2013 & United States & Durham ${ }^{46}$ & 6.8 & 0.920 & 79.2 & 8.3 \\
\hline 2015 & Taiwan & Taipei $^{47}$ & 6.5 & 0.738 & 76.0 & 3.1 \\
\hline 2015 & United States & Colonial Heigths ${ }^{48}$ & 4.09 & 0.920 & 79.2 & 8.3 \\
\hline 2016 & Finland & Turku $u^{49}$ & 11.6 & 0.895 & 81.0 & 9.7 \\
\hline 2016 & Austria & Styria, Tyrol $^{49}$ & 8.2 & 0.893 & 81.6 & 11.2 \\
\hline 2016 & Croatia & Slavonski Brod, Zadar, Zagreb ${ }^{49}$ & 26.9 & 0.827 & 77.5 & 7.8 \\
\hline 2016 & Croatia & Koprivinica, Rijeka, Split ${ }^{49}$ & 11.1 & 0.827 & 77.5 & 7.8 \\
\hline 2016 & Czech Republic & Hredec Kralove $e^{49}$ & 8.4 & 0.878 & 78.8 & 7.4 \\
\hline 2016 & Greece & Athens ${ }^{49}$ & 28.9 & 0.866 & 81.1 & 8.1 \\
\hline 2016 & Poland & Cracow. Poznan ${ }^{49}$ & 16.5 & 0.855 & 77.6 & 6.3 \\
\hline 2016 & Serbia & Novi Sad ${ }^{49}$ & 9.2 & 0.78 & 75.0 & 10.4 \\
\hline
\end{tabular}


Factors contributing to these figures concern the heavy traffic of vehicles on public roads those cities, which hinders the circulation of ambulances and is an impediment to achieving adequate response times as prescribed by the WHO. ${ }^{2}$ In Brazil, there is no specific regulation that specifies limitations for response times in $\mathrm{EMS}^{11-13,38}$.

Another indicator evaluated by the United Nations Development Programmer is the proportionality of health spending relative to the GDP and the life expectancy of the countries ${ }^{38-40}$. Evaluating this indicator, it was observed that there is no significant correlation between the GDP percentage allocated to health spending and the response time of the service under discussion (Table 1). That is, the performance of the response time of emergency medical services does not depend on the amount of resource available for health in a country ${ }^{41}$. The idea that arises the present from this discussion is centered on the management of the resource derived from the
GDP, that is, if it is being used to promote the operational efficiency of emergency medical assistance services.

Furthermore, other factors that should influence the response performance of medical teams are demographic density, localities (size), public health policies and traffic conditions in public roads. Figure 5 represents a summary of the median of the indicators presented in Table 1 per continent ${ }^{11,18}$.

The choice of the median for the development of this graph was due to sensitivity, which allows the adequate understanding of the indicators from the continental point of view, according to our review ${ }^{42}$. Figure 5 shows that there is a predominance of response time in significant nonconformity with what is prescribed by the World Health Organization ( 8 minutes) in places where there is low life expectancy, low public investment in health and follow average human development index $(\mathrm{HDI})^{43}$.

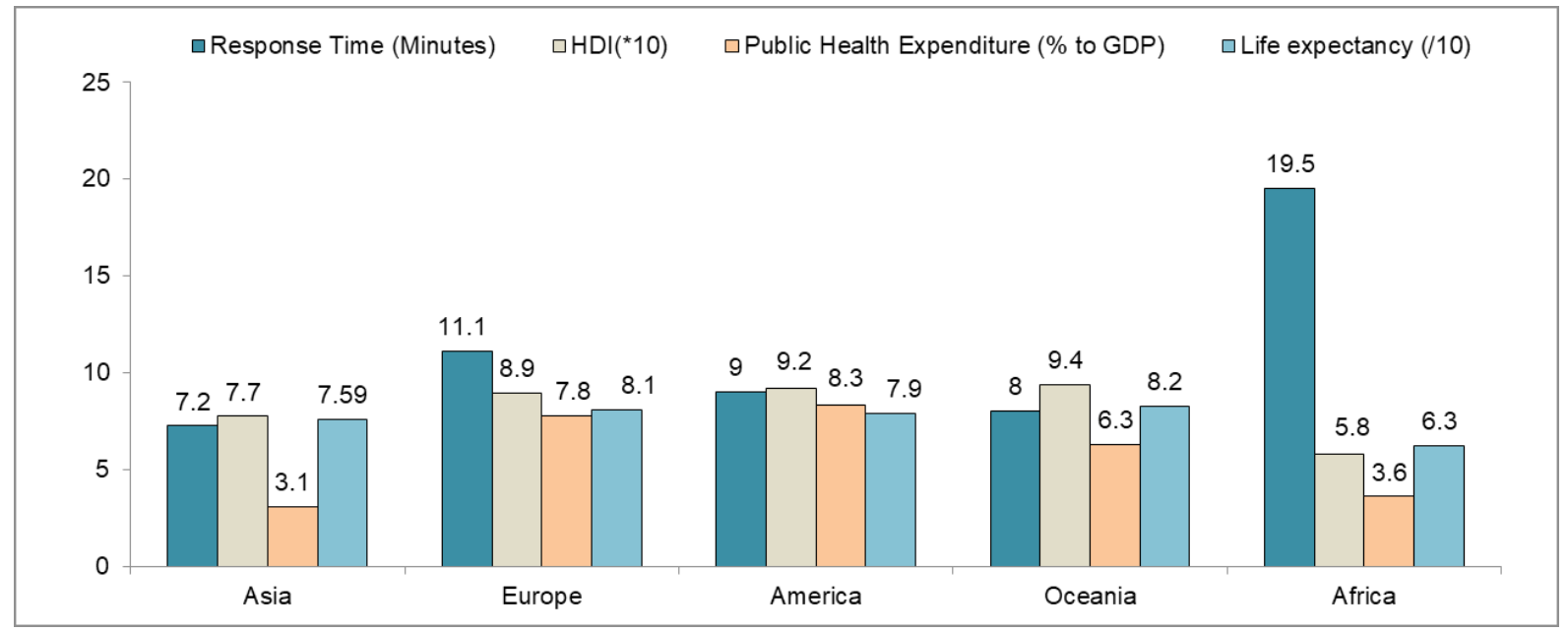

Figure 5 - Median of Response Time, Public Health and HDI.

In locations where response time happens within the WHO's determined their conformity, can be seen high life expectancy, higher GDP percentage, more public investment in the area, expenditure, very high human development index and high life expectancy were identified ${ }^{42-44}$.

The exceptional case of Asia presents 
a median response time lower than that registered in other continents, although the GDP percentage spent on health is the lowest recorded value, which raises the discussion of the public policies used by the governments of the countries of that continent and the distribution of resources for the provision of these policies and their alignment with the efficiency of routine EMS operations ${ }^{45}$.

Asia has a shorter mean response time (7.3 minutes), followed by Oceania (8.0 minutes). In this continent was identified only one country (Australia) that presented city (Melbourne) whose emergency medical service measures indicator response time ${ }^{46-48}$. In Africa only one country (Ghana) presented cities (Kumasi, Accra and Tamale) where in emergency medical service measures indicator response time (19 minutes). America and Europe have a median response time of 9 to 11 minutes, respectively ${ }^{49}$. Due to the representativeness of North American cities in the measurement of the response time of emergency medical services, a median human development index for the Americas was equivalent to 0.920 , value corresponding to the US HDI. This does not reflect the HDI reality of the entire American continent ${ }^{50}$.

\section{Conclusions}

In conclusion, this review has shown that, in several countries around the world, there is an interest of health institutions responding urgently and in an emergency to the quantification of response time, and there is a consensus that this indicator is fundamental to understanding routine EMS.

Due to the importance of the topic, it is necessary to stimulate the development of other studies that seek to understand the factors correlated to the response time, which will allow a scientifically validated understanding of what can be done to reduce it.

\section{References}

1. McDonald RI. The effectiveness of conservation interventions to overcome the urban-environmental paradox. Ann N Y Acad Sci. 2015 Oct;1355:1-14. doi: 10.1111/ nyas.12752.

2. Beninde J, Veith $M$, Hochkirch A. Biodiversity in cities needs space: a meta-analysis of factors determining intra-urban biodiversity variation. Ecol Lett. 2015 Jun;18(6):581-92. doi: 10.1111/ele.12427.

3. Kim SH, Lee $\mathrm{YH}$. Iterative optimization algorithm with parameter estimation for the ambulance location problem. Health Care Manag Sci. 2016 Dec;19(4):362-82. PMID: 26143594.

4. Peyravi M, Khodakarim S, Örtenwall $P$, Khorram-Manesh A. Does temporary location of ambulances ("fluid deployment") affect response times and patient outcome? Int J Emerg Med. 2015 Dec;8(1):37. doi: 10.1186/s12245-015-0084-1.

5. Nogueira LC Jr, Pinto LR, Silva PM. Reducing Emergency Medical Service response time via the reallocation of ambulance bases. Health Care Manag Sci. 2016 Mar;19(1):3142. doi: 10.1007/s10729-014-9280-4.

6. Aringhieri R, Carello G, Morale D. Supporting decision making to improve the performance of an Italian Emergency Medical Service. Ann Oper Res. 2016;236:131-48. doi: 10.1007/ s10479-013-1487-0.

7. Lawner BJ, Hirshon JM, Comer AC, Nable JV, Kelly J, Alcorta RL, Pimentel L, Tupe CL, Vanhoy MA, Browne BJ. The impact of a freestanding ED on a regional emergency medical services system. Am J Emerg Med. 2016 Aug;34(8):1342-6. doi: 10.1016/j. ajem.2015.11.042.

8. Vile JL, Gillard JW, Harper PR, Knight VA. Timedependent stochastic methods for managing and scheduling Emergency Medical Services. Oper Res Heal Care. 2016;8:42-52. doi: 10.1016/j.orhc.2015.07.002.

9. Nogueira Junior LC. Um estudo para redução do tempo de resposta do SAMU de Belo Horizonte através da realocação das bases de operação [Tese]. Belo Horizonte: Universidade Federal de Minas Gerais; 2011.

10.Andrade LACG, Cunha CB. An ABC heuristic for optimizing moveable ambulance station 
location and vehicle repositioning for the city of São Paulo. Int Trans Oper Res. 2015;22. doi: 10.1111/itor.12160.

11.Takeda RA, Widmer JA, Morabito R. Analysis of ambulance decentralization in an urban emergency medical service using the hypercube queueing model. Comput Oper Res. 2007;34(3):727-41.

12.Leardi R. Experimental design in chemistry: a tutorial. Anal Chim Acta. 2009 Oct 12;652(12):161-72. doi: 10.1016/j.aca.2009.06.015.

13.Valeri L, Vanderweele TJ. Mediation analysis allowing for exposure-mediator interactions and causal interpretation: theoretical assumptions and implementation with SAS and SPSS macros. Psychol Methods. 2013 Jun;18(2):137-50. doi: 10.1037/a0031034.

14.Krive J. Patient outcomes as transformative mechanisms to bring health information technology industry and research informatics closer together. Stud Health Technol Inform. 2015;216:410-3. PMID: 26262082.

15.Kuo CW, See LC, Tu HT, Chen JC. Adult outof-hospital cardiac arrest based on chain of survival in Taoyuan County, northern Taiwan. J Emerg Med. 2014 Jun;46(6):78290. doi: 10.1016/j.jemermed.2013.08.026.

16.Pulver A, Wei R, Mann C. Locating AED enabled medical drones to enhance cardiac arrest response times. Prehosp Emerg Care. 2016 May-Jun;20(3):378-89. doi: 10.3109/10903127.2015.1115932.

17.Park GJ, Song KJ, Shin SD, Lee KW, Ahn KO, Lee EJ, Hong KJ, Ro YS. Timely bystander CPR improves outcomes despite longer EMS times. Am J Emerg Med. 2017 Aug;35(8):1049-55. doi: 10.1016/j. ajem.2017.02.033.

18.von Vopelius-Feldt J, Coulter A, Benger J. The impact of a pre-hospital critical care team on survival from out-of-hospital cardiac arrest. Resuscitation. 2015 Nov;96:290-5. doi: 10.1016/j.resuscitation.2015.08.020.

19. Nichol G, Cobb LA, Yin L, Maynard C, Olsufka M, Larsen J, McCoy AM, Sayre MR. Briefer activation time is associated with better outcomes after out-of-hospital cardiac arrest. Resuscitation. 2016 Oct;107:139-44. doi: 10.1016/j.resuscitation.2016.06.040.

20.Lam SS, Nguyen FN, Ng YY, Lee VP, Wong $\mathrm{TH}$, Fook-Chong SM, Ong ME. Factors affecting the ambulance response times of trauma incidents in Singapore. Accid Anal Prev. 2015 Sep;82:27-35. doi: 10.1016/j. aap.2015.05.007.

21.Nordberg $P$, Jonsson $M$, Forsberg $S$, Ringh M, Fredman D, Riva G, Hasselqvist-Ax I, Hollenberg J. The survival benefit of dual dispatch of EMS and fire-fighters in out-ofhospital cardiac arrest may differ depending on population density--a prospective cohort study. Resuscitation. 2015 May;90:143-9. doi: 10.1016/j.resuscitation.2015.02.036.

22. Deasy C, Bray J, Smith K, Harriss L, Morrison C, Bernard S, Cameron P. Traumatic out-of-hospital cardiac arrests in Melbourne, Australia. Resuscitation. 2012 Apr;83(4):465-70. doi: 10.1016/j. resuscitation.2011.09.025.

23.erhaert DV, Bonnes JL, Nas J, Keuper W, van Grunsven PM, Smeets JL, de Boer MJ, Brouwer MA. Termination of resuscitation in the prehospital setting: A comparison of decisions in clinical practice vs. recommendations of a termination rule. Resuscitation. 2016 Mar;100:60-5. doi: 10.1016/j.resuscitation.2015.12.014.

24.van Barneveld TC, Bhulai S, van der Mei RD. A dynamic ambulance management model for rural areas: computing redeployment actions for relevant performance measures. Health Care Manag Sci. 2017 Jun;20(2):16586. doi: 10.1007/s10729-015-9341-3.

25. Hiltunen PV, Silfvast TO, Jäntti TH, Kuisma MJ, Kurola JO; Finnresusci Prehospital Study Group. Emergency dispatch process and patient outcome in bystanderwitnessed out-of-hospital cardiac arrest with a shockable rhythm. Eur J Emerg Med. 2015 Aug;22(4):266-72. doi: 10.1097/ MEJ.0000000000000151.

26.Zaffar MA, Rajagopalan HK, Saydam C, Mayorga M, Sharer E. Coverage, survivability or response time: A comparative study of performance statistics used in ambulance location models via simulation-optimization. Oper Res Heal Care. 2016;11:1-12. doi: 10.1016/j.orhc.2016.08.001.

27. Baptista S, Oliveira RC. A case study on the application of an approximated hypercube model to emergency medical systems management. Cent Eur J Oper Res. 2012;20:559-81. doi: 10.1007/s10100-0100187-y.

28.Knight VA, Harper PR, Smith L. Ambulance 
allocation for maximal survival with heterogeneous outcome measures. Omega. 2012;40.doi:10.1016/j.omega.2012.02.003.

29.Chanta S, Mayorga ME, McLay LA. Improving emergency service in rural areas: a biobjective covering location model for EMS systems. Ann Oper Res. 2014;221:133. doi: 10.1007/s10479-011-0972-6.

30.Liu Y, Li Z, Liu J, Patel H. Vehicular crash data used to rank intersections by injury crash frequency and severity. Data Brief. 2016 Jul 1;8:930-3. doi: 10.1016/j.dib.2016.06.046.

31.Liu Y, Li Z, Liu J, Patel H. A double standard model for allocating limited emergency medical service vehicle resources ensuring service reliability. Transp Res Part C Emerg Technol. 2016;69:120-33. doi: 10.1016/j. trc.2016.05.023.

32. Osteras O, Bratteb $\varnothing \mathrm{G}$, Heltne JK. Helicopterbased emergency medical services for a sparsely populated region: a study of 42,500 dispatches. Acta Anaesthesiol Scand. 2016;60:659-67. doi: 10.1111/aas.12673.

33.Saner $H$, Morger C, Eser P, von Planta M. Dual dispatch early defibrillation in out-of-hospital cardiac arrest in a mixed urban-rural population. Resuscitation. 2013 Sep;84(9):1197-202. doi: 10.1016/j. resuscitation.2013.02.023.

34.Dibene JC, Maldonado Y, Vera C, de Oliveira $M$, Trujillo $L$, Schütze $O$. Optimizing the location of ambulances in Tijuana, Mexico. Comput Biol Med. 2017 Jan 1;80:107-15. doi: 10.1016/j.compbiomed.2016.11.016.

35.Griffin R, McGwin G. Emergency medical service providers' experiences with traffic congestion. J Emerg Med. 2013;44:398405. doi: 10.1016/j.jemermed.2012.01.066.

36.van Barneveld TC, Bhulai S, van der Mei $\mathrm{RD}$. The effect of ambulance relocations on the performance of ambulance service providers. Eur J Oper Res. 2015;252:257-69. doi: 10.1016/j.ejor.2015.12.022.

37.Ströhle M, Paal P, Strapazzon G, Avancini G, Procter E, Brugger $H$. Defibrillation in rural areas. Am J Emerg Med. 2014 Nov;32(11):1408-12. doi: 10.1016/j. ajem.2014.08.046.

38.Gholipour C, Shams VahdatiS, Notash M, Miri $\mathrm{SH}$, Ghafouri RR. Success rate of pre-hospital emergency medical service personnel in implementing pre-hospital trauma life support guidelines on traffic accident victims. Turkiye Acil Tip Derg. 2014;14:71-4. doi: 10.5505/1304.7361.2014.50103.

39.Zakariah A, Stewart BT, Boateng E, Achena C, Tansley G, Mock C. The birth and growth of the National Ambulance Service in Ghana. Prehosp Disaster Med. 2017 Feb;32(1):8393. doi: $10.1017 /$ S1049023X16001151.

40.Langabeer JR 2nd, Dellifraine J, Fowler R, Jollis JG, Stuart L, Segrest W, Griffin R, Koenig W, Moyer P, Henry TD. Emergency medical services as a strategy for improving ST-elevation myocardial infarction system treatment times. J Emerg Med. 2014 Mar;46(3):355-62. doi: 10.1016/j. jemermed.2013.08.112.

41.Lawner BJ, Hirshon JM, Comer AC, Nable JV, Kelly J, Alcorta RL, Pimentel L, Tupe CL, Vanhoy MA, Browne BJ. The impact of a freestanding ED on a regional emergency medical services system. Am J Emerg Med. 2016 Aug;34(8):1342-6. doi: 10.1016/j. ajem.2015.11.042.

42. Belzunegui T, Gradín C, Fortún M, Cabodevilla A, Barbachano A, Sanz JA. Major trauma registry of Navarre (Spain): the accuracy of different survival prediction models. Am J Emerg Med. 2013 Sep;31(9):1382-8. doi: 10.1016/j.ajem.2013.06.026.

43.Sarac T, Akyol E. Reducing ambulance response time: A case study. CIE 2014 - 44th Int Conf Comput Ind Eng IMSS 2014 - 9th Int Symp Intell Manuf Serv Syst Jt Int Symp. Soc Impacts Dev Informat [Internet]. 2014;7685.

44.Ono $Y$, Hayakawa $M$, lijima $H$, Maekawa K, Kodate A, Sadamoto $Y$, Mizugaki A, Murakami H, Katabami K, Sawamura A, Gando S. The response time threshold for predicting favourable neurological outcomes in patients with bystanderwitnessed out-of-hospital cardiac arrest. Resuscitation. 2016;107:65-70. doi: 10.1016/j.resuscitation.2016.08.005.

45.Funada A, Goto Y, Maeda T, Teramoto R, Hayashi K, Yamagishi M. Improved survival with favorable neurological outcome in elderly individuals with out-of-hospital cardiac arrest in Japan - A nationwide observational cohort study. Circ J. 2016 Apr 25;80(5):1153-62. doi: 10.1253/circj. CJ-151285.

46.Chen TT, Ma MHM, Chen FJ, Hu FC, Lu YC, Chiang WC, Ko PC. The relationship 
between survival after out-of-hospital cardiac arrest and process measures for emergency medical service ambulance team performance. Resuscitation. 2015;97:55-60. doi: 10.1016/j.resuscitation.2015.04.035.

47.Bagai A, McNally BF, Al-Khatib SM, Myers JB, Kim S, Karlsson L, Torp-Pedersen C, Wissenberg M, van DiepenS, Fosbol EL, Monk L, Abella BS, Granger CB, Jollis JG. Temporal differences in out-of-hospital cardiac arrest incidence and survival. Circulation. 2013 Dec 17;128(24):2595-602. doi: 10.1161/ CIRCULATIONAHA.113.004164.

48.Anderson DW, Dhindsa HS, Wan W, Salot D. Does the implementation of an advanced life support Quick Response Vehicle (QRV) in an integrated Fire/SEM system improve patient contact response time? Prehosp
Disaster Med. 2015 Aug;30(4):382-4. doi: 10.1017/S1049023X15004732.

49.Nikolaou N, Castrén $M$, Monsieurs KG, Cimpoesu D, Georgiou M, Raffay V, Koster $R$, Hunyadi-Antičević $S$, Truhlář A, Bossaert L; EUROCALL investigators. Time delays to reach dispatch centres in different regions in Europe. Are we losing the window of opportunity? - The EUROCALL study. Resuscitation. 2017 Feb;111:8-13. doi: 10.1016/j.resuscitation.2016.10.026.

50.'t Hoen EF, Hogerzeil HV, Quick JD, Sillo HB. A quiet revolution in global public health: The World Health Organization's Prequalification of Medicines Programme. J Public Health Policy. 2014 May;35(2):13761. doi: 10.1057/jphp.2013.53.

\section{Correspondence:}

Irami Araújo-Filho

Hospital Universitário Onofre Lopes - Núcleo

de Cirurgia Experimental/UFRN

Avenida Nilo Peçanha, 620

59012-300 Natal - RN Brasil

Tel.: (55 84)98876-0206

irami.filho@uol.com.br

Received: Aug 06, 2018

Review: Oct 08, 2018

Accepted: Nov 03, 2018
Conflict of interest: none

Financial source: CAPES

\begin{abstract}
${ }^{1}$ Research performed at Nucleus of Experimental Surgery, Department of Surgery and the Department of Production Engineering, Universidade Federal do Rio Grande do Norte (UFRN), Natal-RN, Brazil.
\end{abstract}

